\title{
FMR and EPR in Ni@C Nanocomposites: Size and Concentration Effects
}

\author{
E. G. Sharoyan ${ }^{a}$, A. A. Mirzakhanyan ${ }^{a}$, H. T. Gyulasaryan ${ }^{a}$, \\ A. N. Kocharian ${ }^{b}$, and A. S. Manukyan ${ }^{a^{*}}$ \\ ${ }^{a}$ Institute for Physical Research, NAS of Armenia, Ashtarak, Armenia \\ ${ }^{b}$ California State University, Los Angeles, USA \\ *manukyan.ipr@gmail.com
}

Received December 26, 2016

\begin{abstract}
One-domain Ni@C nanoparticles encapsulated in carbon coating have been investigated depending on the size and concentration of $\mathrm{Ni}$ in carbon. The nanoparticles of nickel were prepared with the average diameters changing in a broad range of $4-45 \mathrm{~nm}$, and the concentration of $\mathrm{Ni}$ in $\mathrm{C}$ varies in 2-12 wt \%. To prepare the $\mathrm{Ni} @ \mathrm{C}$ nanocomposites the solid solutions of nickel phthalocyanine-metal-free phthalocyanine $(\mathrm{NiPc})_{x}\left(\mathrm{H}_{2} \mathrm{Pc}\right)_{1-x}, 0 \leq x \leq 1$ were synthesized and the solidphase pyrolysis of these compounds was performed. In the case of ultradispersive Ni nanoparticles (the interval of quantum dots is $1-10 \mathrm{~nm}$ ), a considerable shift of the resonance field and broadening of resonance absorption field were revealed in the spectra of FMR at room temperature. The data were interpreted taking into account the essential contribution of the surface magnetic anisotropy, the magnetic field of which far exceeds the magnetic field of volume anisotropy.
\end{abstract}

DOI: $10.3103 / \mathrm{S} 1068337217020086$

Keywords: nanocomposite, FMR, EPR, phthalocyanine, carbon, nickel

\section{INTRODUCTION}

The magnetic nanoparticles of metals are of great interest both from the scientific point of view and in connection with the numerous possible practical applications. In particular, they can be used in biomedicine, spintronics, as catalysts, sensors, supercapacitors, etc. [1-9]. For applications of considerable interest are the magnetic nanoparticles of metals encapsulated in the carbon (the graphitelike) shell of M@C, because the carbon matrix is stable both chemically and thermally. The carbon shell not only protects the metal nanoparticles from oxidation but also protects them from an aggregation. In addition, carbon is a biocompatible material.

To obtain the metal nanoparticles in various carbon matrices, we have developed a method based on the solid-state pyrolysis of organometallic compounds. The method is simple, one-stage, safe and economical. The results of solid-phase pyrolysis of polycrystalline metal-phthalocyanine powders MPc $\left[\mathrm{M}\left(\mathrm{C}_{32} \mathrm{~N}_{8} \mathrm{H}_{16}\right), \mathrm{M}=\mathrm{Ni}, \mathrm{Cu}, \mathrm{Fe}, \mathrm{Co}\right.$ and $\left.\mathrm{Zn}\right]$ are reported in [10-12]. We have also developed the method of solid phase pyrolysis of non-metallic phthalocyanine alloy $\mathrm{H}_{2} \mathrm{Pc}\left[\mathrm{H}_{2}\left(\mathrm{C}_{32} \mathrm{~N}_{8} \mathrm{H}_{16}\right)\right]$. By solid-phase pyrolysis of polycrystalline samples, the carbon microspheres consisting of nanographite crystallites and amorphous carbon have been produced [13-15]. Varying the parameters of solid-state pyrolysis and dilution of metal-phthalocyanine powders with the non-metal phthalocyanine give a unique opportunity to obtain the metal nanoparticles with sizes from one to $200 \mathrm{~nm}$; at that, the atomic concentration of the 
metal in carbon varies from zero to $3 \mathrm{at} \%$. One of the tasks of this paper was to obtain the solid solutions $(\mathrm{NiPc})_{x}\left(\mathrm{H}_{2} \mathrm{Pc}\right)_{1-x}$, where $0 \leq x \leq 1$.

The nanoparticles of Ni encapsulated in carbon matrix, the Ni@C nanocomposites, were studied in [16-24]. Despite a considerable number of works, the systematic study of magnetic properties of nickel nanoparticles depending on the size and concentration of the metal is absent. In the present work by the pyrolysis of solid solutions $(\mathrm{NiPc})_{x}\left(\mathrm{H}_{2} \mathrm{Pc}\right)_{1-x}$, we obtained the $\mathrm{Ni} @ \mathrm{C}$ nanocomposites by changing the composition of solutions $x$ and the pyrolysis parameters (temperature, time and pressure), in which the average size of nanoparticles of nickel (a diameter) is distributed in the range of 4-45 $\mathrm{nm}$. The size range of Ni nanoparticles studied by us also includes a range of 1-10 nm, which refers to quantum dots, where it is essential to take into account quantum states and surface effects, in particular, the surface magnetic anisotropy, which results to an increase in the effective magnetic anisotropy constant $K_{\text {eff. }}$

The magnetic properties of the samples were studied by the methods of ferromagnetic and electron paramagnetic resonances, that is, by the FMR and EPR techniques. The dependences of the FMR and EPR parameters on the concentration and sizes of nickel nanoparticles are investigated. The influence of the surface magnetic anisotropy on the FMR parameters in the case of ultradisperse Ni nanoparticles is revealed.

\section{EXPERIMENTAL}

Earlier we investigated the solid-phase pyrolysis of nickel phthalocyanine powders NiPc $\left[\mathrm{Ni}\left(\mathrm{C}_{32} \mathrm{~N}_{8} \mathrm{H}_{16}\right)\right]$, as a result of which the nickel nanoparticles were obtained in various carbon matrices $[10,11]$. At that the atomic nickel content is $3 \mathrm{at} \%(12 \mathrm{wt} \%)$. We also found that in the solid-phase pyrolysis of the non-metallic phthalocyanine $\mathrm{H}_{2} \mathrm{Pc}\left[\mathrm{H}_{2}\left(\mathrm{C}_{32} \mathrm{~N}_{8} \mathrm{H}_{16}\right)\right]$, carbon microspheres consisting of nanographite crystallites and an amorphous carbon are formed [13]. In the present work, we obtained the solid solutions of nickel-phthalocyanine-metal-free phthalocyanine $(\mathrm{NiPc})_{x}\left(\mathrm{H}_{2} \mathrm{Pc}\right)_{1-x}$, where $0 \leq x \leq 1$. The solid phase pyrolysis of these solid solutions can be represented as the following chemical reaction:

$$
\left[\mathrm{Ni}\left(\mathrm{C}_{32} \mathrm{~N}_{8} \mathrm{H}_{16}\right)\right]_{x}\left[\mathrm{H}_{2}\left(\mathrm{C}_{32} \mathrm{~N}_{8} \mathrm{H}_{16}\right)\right]_{1-x} \underset{-8 \mathrm{H}_{2},-4 \mathrm{~N}_{2}}{\stackrel{T_{\mathrm{pr}}, t_{\mathrm{py}}, p}{\longrightarrow}} \mathrm{Ni}_{x}+32 \mathrm{C}, \quad 0 \leq x \leq 1,
$$

where $T_{\mathrm{pyr}}$ is the pyrolysis temperature, $t_{\mathrm{pyr}}$ the pyrolysis time and $p$ the pressure in the reaction ampoule. The pyrolysis conditions for all tested samples, except for $\mathrm{S}_{2.5}$, were the same: $T_{\mathrm{pyr}}=700^{\circ} \mathrm{C}, t_{\mathrm{pyr}}=30 \mathrm{~min}$. For the purpose of obtaining the nanoparticles of small sizes but with a high nickel concentration, the pyrolysis time of sample $\mathrm{S}_{2.5}$ was chosen considerably less than $30 \mathrm{~min}$. To obtain nanoparticles with large sizes, the pyrolysis time of sample $S_{3}^{*}$ was $300 \mathrm{~min}$.

It is also not difficult to obtain an equation that relates the nickel concentration in the resulting compounds, expressed in the atomic percentages of $c_{\mathrm{Ni}}$, with allowance of values of $x$ used in the reaction (1):

$$
c_{\mathrm{Ni}}=\frac{x}{32+x} 100 \text { at } \% \text {. }
$$

A wide set of samples with atomic concentrations $c_{\mathrm{Ni}}$ equal to $0,0.5,0.75,1,1.5,2,2.5$ and 3 at $\%$ is synthesized. Note that the distribution of nickel nanoparticles in the carbon matrix is not ordered but uniform. The average values of nickel concentration taken in different sections of the sample ${ }_{C_{\mathrm{Ni}}}>$ coincide within the accuracy to $10 \%$ with the calculated values according to the formula (2). The samples with the corresponding atomic concentrations will be denoted below as $S_{0}, S_{0.5}, S_{0.75}, S_{1}, S_{1.5}, S_{2}, S_{2.5}, S_{3}$ and 
$\mathrm{S}_{3}^{*}$. The weight percentages corresponding to these samples are equal to $0,2,3,4,6,8,10$ and $12 \mathrm{wt} \%$. The average sizes $\langle d>$ of nickel nanoparticles are $0,4,6,17,20,23,12,26$ and $45 \mathrm{~nm}$.

The elemental composition and sizes of the obtained nanoparticles were examined using a transmission electron microscope (TEM) FEI Tecnai F20 Supertwin and an energy dispersive X-ray microanalyzer INCA Energy 300. The structure of the nanocomposites was determined with use of X'PERT PRO X-ray diffractometer (the $\mathrm{Cu} K \alpha$ radiation).

The ferromagnetic characteristics of nickel nanoparticles, as well as the paramagnetism of the carbon matrix, were measured at $300 \mathrm{~K}$ according to the standard scheme using an X-band EPR spectrometer with the fixed excitation frequency $\omega_{0}=9.3 \mathrm{GHz}$ by the frequency tuning control of an external magnetic field. The observed signals are the first derivative of the absorption curve, and the line widths are the distance between the peaks of the first derivative $\Delta H_{\mathrm{FMR}} \equiv \Delta H_{\mathrm{pp}}$.

\section{RESULTS AND DISCUSSION}

\subsection{Structural studies. X-ray diffraction and electron microscopy}

Figure 1 shows X-ray diffraction spectra of samples obtained at room temperature. They contain peaks from $\mathrm{Ni}$ and $\mathrm{C}$ : the wide peak of about $26^{\circ}$ corresponds to a graphite-like carbon structure; the narrow peaks correspond to the nickel nanocrystals with a face-centered cubic lattice. It follows from the Fig. 1 that the degree of graphitization of carbon sharply increases, as the concentration of nickel increases.

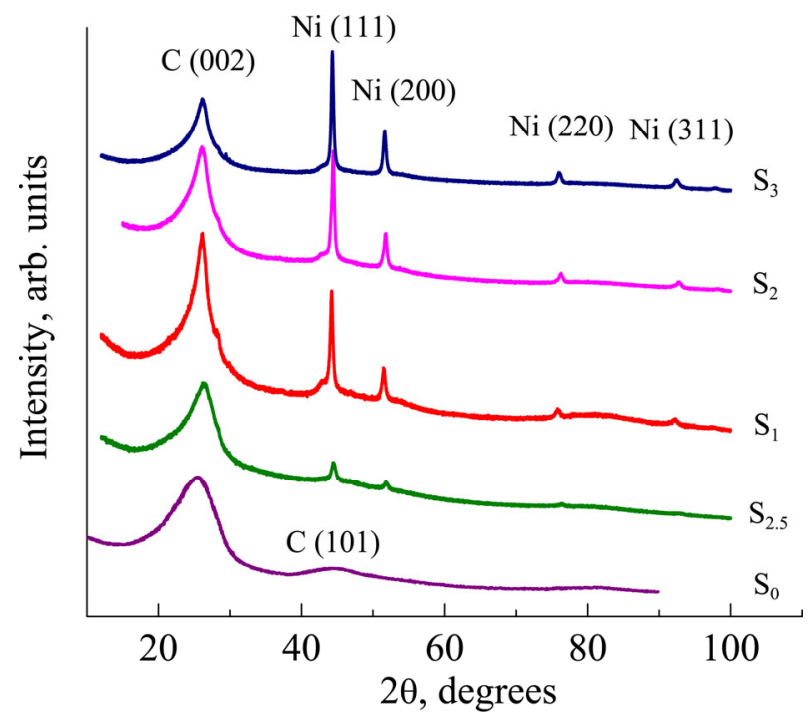

Fig. 1. X-ray diffraction spectra of samples $\mathrm{S}_{0}, \mathrm{~S}_{1}, \mathrm{~S}_{2}, \mathrm{~S}_{2.5}$, and $\mathrm{S}_{3}$.

The TEM images (Fig. 2) show Ni nanoparticles that are close to the spherical shape and covered with a graphite-like shell, which protects them from oxidation and aggregation.

3.2. Dependence of the FMR and EPR parameters on the concentration and sizes of Ni nanoparticles. The contribution of the surface magnetic anisotropy.

Figure 3 shows the FMR and EPR spectra of Ni@C nanocomposites samples. The concentration of nickel varies from zero to three at $\%$. In the spectra, the narrow signal is the EPR one, which is due to the 

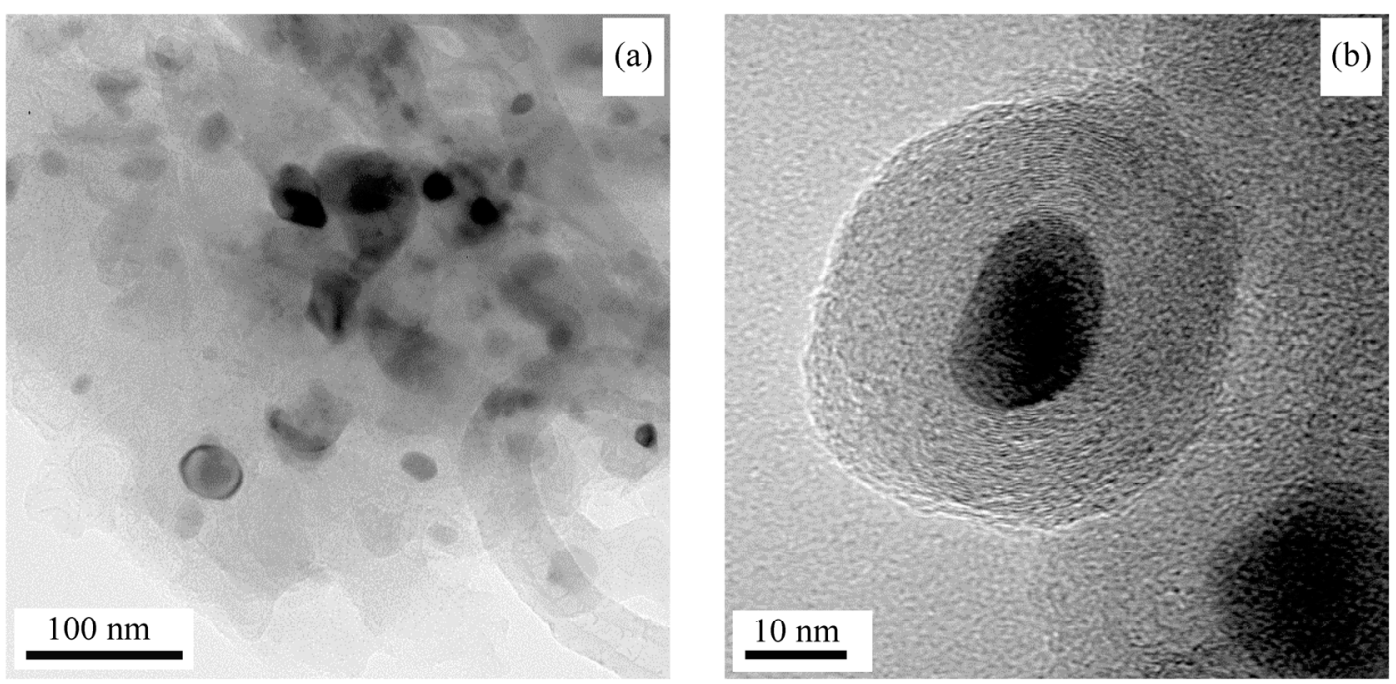

Fig. 2. TEM images of $\mathrm{Ni} @ \mathrm{C}$ nanocomposites, the sample $\mathrm{S}_{2}$.

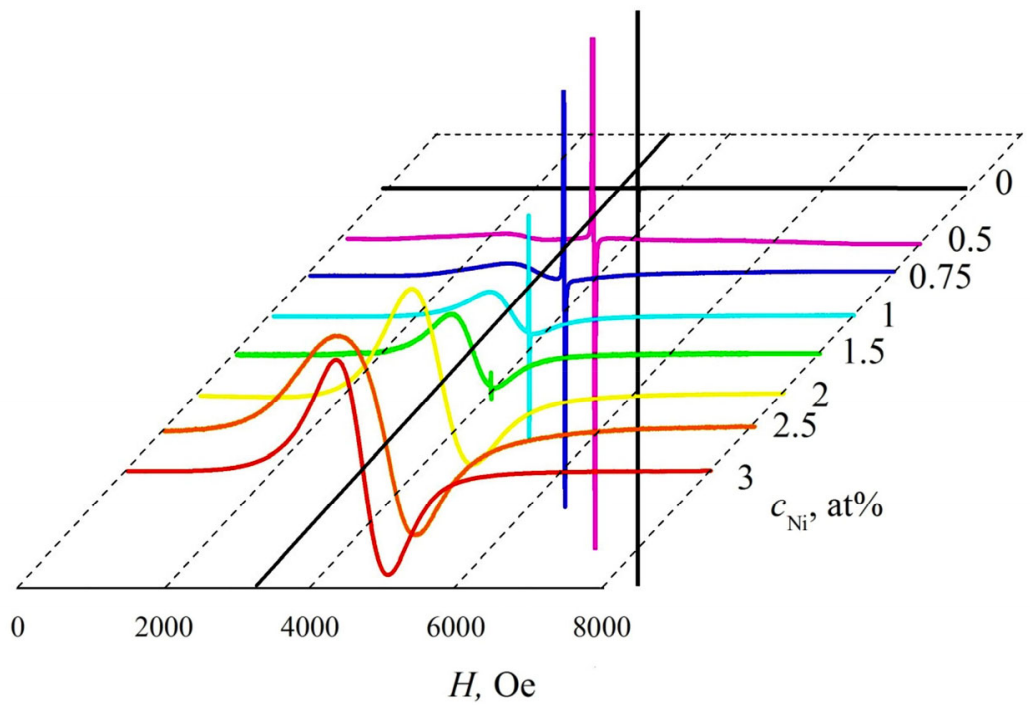

Fig. 3. FMR and ESR spectra measured in the X-band, depending on the atomic concentration of nickel $c_{\mathrm{Ni}}$.

carbon matrix and, apparently, by unpaired $\pi$-electrons in nanographite crystallites which fill the carbon microspheres [13-15]. The wide signal is the FMR signal due to nickel $d$-electrons in Ni@C nanocomposites. The samples $\mathrm{S}_{0}$ that do not contain nickel $\left(c_{\mathrm{Ni}}=0\right)$ have an intense EPR signal of $\sim 5 \times$ $10^{19} \mathrm{spin} / \mathrm{g}$ and a very narrow signal width $(1 \mathrm{Oe})$. However, in the presence of nickel in samples of $\mathrm{Ni@C} \mathrm{nanocomposites,} \mathrm{there} \mathrm{is} \mathrm{a} \mathrm{sharp} \mathrm{drop} \mathrm{in} \mathrm{the} \mathrm{integrated} \mathrm{intensity} \mathrm{of} \mathrm{the} \mathrm{EPR} \mathrm{signal} \mathrm{even} \mathrm{at} \mathrm{low}$ nickel concentrations $c_{\mathrm{Ni}}$. These changes are presented in Fig. 4b. At the nickel concentration of 1.5$2 \mathrm{at} \%$, the integral intensity of the narrow signal is practically zero, while the line width is broadened relatively little from 1 to 3.5 Oe by the change in the nickel concentration from 0 to 1.5 at $\%$, respectively. This effect is the result of the interaction of nickel nanoparticles with the carbon matrix, namely, caused by electron transfers from the graphite-like carbon shell to the nickel nanoparticles. Obviously, these 

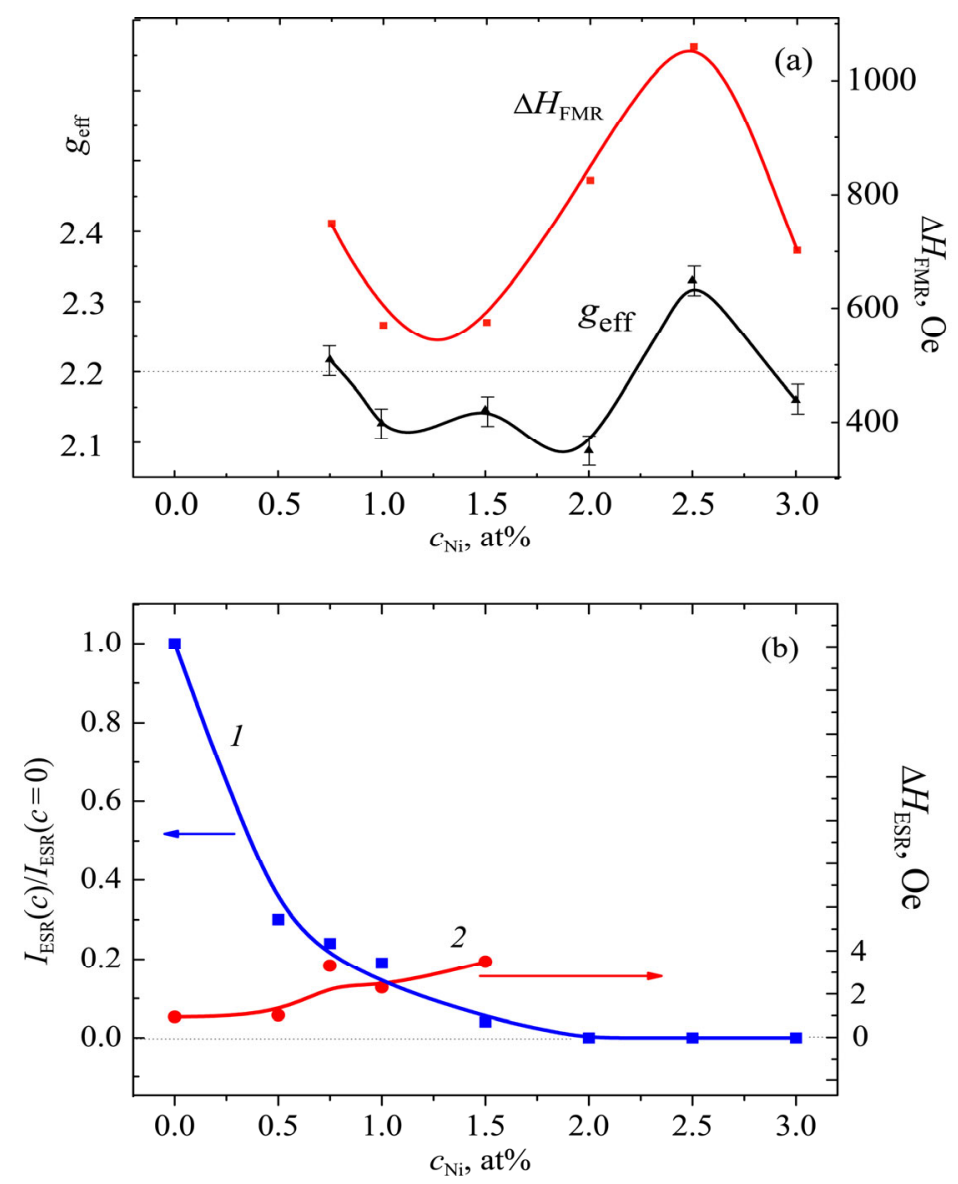

Fig. 4. Dependence of the spectra parameters (a) FMR and (b) EPR on the concentration of nickel.

transitions cause a decrease in the concentration of unpaired $\pi$-electrons, because of which the narrow EPR signal vanishes at $c_{\mathrm{Ni}}$ in the range $1.5-2 \mathrm{at} \%$.

Figure $4 \mathrm{a}$ represents the dependences of main parameters of the FMR spectra in the $\mathrm{Ni} @ \mathrm{C}$ nanocomposites: the effective $g$-factor and the width of the FMR line versus the nickel concentration, and in Fig. 5, the dependence of these parameters on the average diameter of nickel nanoparticles. It is known that a massive sample of nickel is a classical ferromagnetic metal with the Curie temperature of $631 \mathrm{~K}$, whose $g$-factor is equal to $2.22 \pm 0.02$ [25]. For polycrystalline massive ferromagnets, the resonance field $H_{\text {res }}$ can be represented as $H_{\text {res }}=(\omega / \gamma)-H_{i}$, where $H_{i}$ is an effective internal field, $\omega=2 \pi f_{\mathrm{m}}$ and $\gamma=$ $2 \pi g \mu_{\mathrm{B}} / h$ [26]. In cubic systems, the magnetocrystalline anisotropy is $H_{i}=-2 K_{1} / M_{\mathrm{S}}=H_{\mathrm{a}}$. Because for nickel, $K_{1}$ is negative and $\mathrm{H}_{\mathrm{a}}$ is positive, this shifts the resonance to a lesser field, for nickel $H_{\mathrm{a}}=103$ Oe [27]. The FMR in nanoparticles differs from that of single crystals in that the resonance values of the field are shifted relative to their values in single crystals and the resonance lines have a larger width than in monocrystals. The effective field $B_{\text {eff, }}$ which influences a single-domain particle, is equal to [28, 29]:

$$
B_{\text {eff }}=B_{\text {app }}+B_{\mathrm{d}}+B_{\mathrm{a}},
$$

where $B_{\text {app }}$ is an external magnetic field, $B_{\mathrm{d}}$ a demagnetizing field and $B_{\mathrm{a}}$ the field of magnetocrystalline anisotropy. The fields $B_{\mathrm{a}}$ and $B_{\mathrm{d}}$ determine not only the value of the effective $g$-factor $[25,28]$, they are also the main mechanisms determining the width of the FMR line [30-32]. In the case of almost spherical nanoparticles, the width of the FMR signal is defined as $\Delta H=4 K_{\mathrm{a}} / \pi M$, where $M$ is the saturation 


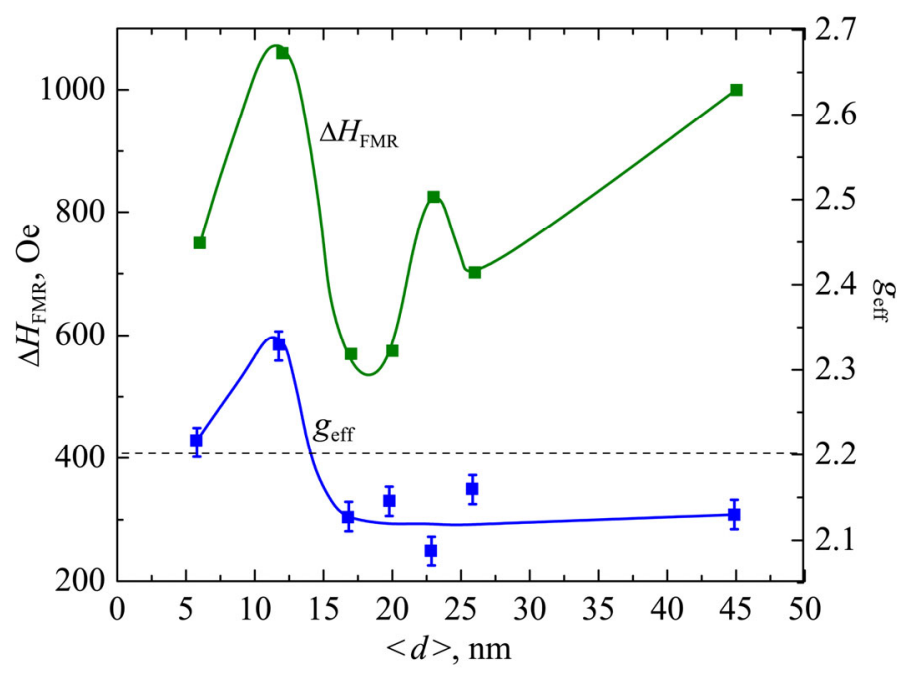

Fig. 5. Dependence of the parameters of the FMR spectra on the mean diameter of nickel nanoparticles.

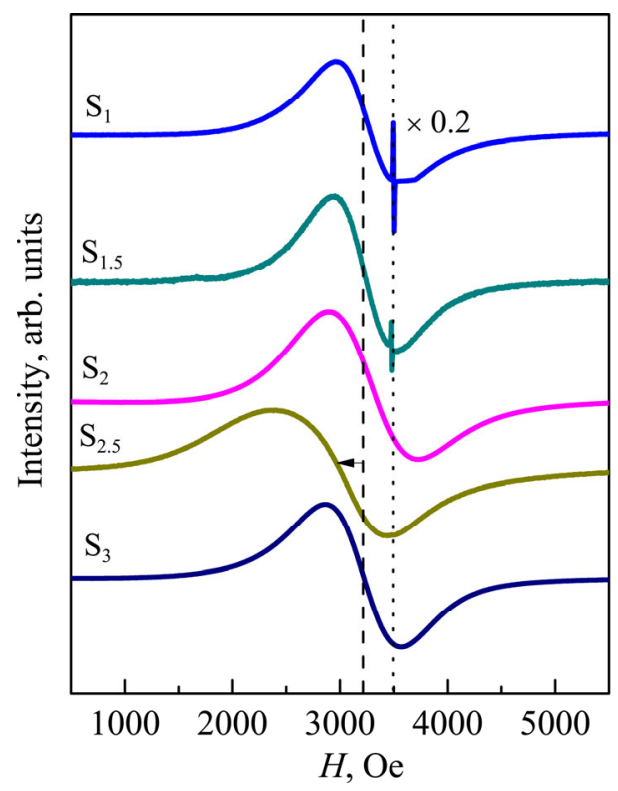

Fig. 6. FMR and ESR spectra of samples $\mathrm{S}_{1}, \mathrm{~S}_{1.5}, \mathrm{~S}_{2}, \mathrm{~S}_{2.5}$, and $\mathrm{S}_{3}$. In sample $\mathrm{S}_{2.5}$, the shift of the FMR field is clearly seen.

magnetization per one $\mathrm{cm}^{3}$ and $K_{\mathrm{a}}$ is the magnetocrystalline anisotropy constant [31]. Figures $4 \mathrm{a}$ and 5 show that in the ultradisperse nickel nanoparticles (the samples $\mathrm{S}_{2.5}$ and $\mathrm{S}_{0.75}$ ) there is a noticeable rise of the effective $g$-factor, $g_{\text {eff }}$, caused by the displacement of the resonant field, and the broadening of the FMR absorption line.

The shift of the ferromagnetic resonance field in sample $S_{2.5}$ is clearly visible in the FMR spectra (Fig. 6). We suppose that the significant shift and the broadening of the FMR signal is due to the contribution of surface anisotropy, which is significant in the ultradisperse nanoparticles.

For spherical nanoparticles, the effective magnetic anisotropy constant $K_{\text {eff }}$ is introduced, which is the sum of two terms - the volumetrical magnetic anisotropy $K_{\mathrm{v}}$ and the surface magnetic anisotropy $K_{\mathrm{s}}[33]$ : 


$$
K_{\mathrm{eff}}=K_{\mathrm{v}}+6 K_{\mathrm{s}} / d,
$$

where $d$ is the diameter of the nanoparticle. The contribution of volumetrical anisotropy does not depend on the particle size, and the surface effect is inversely proportional to the linear dimension of particles.

In $[34,35]$, the effect of various types of magnetic surface anisotropy on the FMR spectra of nanoparticles was studied in details. The cases of uniaxial surface anisotropy, the Neel-Brown anisotropy, are considered in [36, 37] and one-sided surface anisotropy, the Aaroni anisotropy, in [38, 39]. The influence of all considered types of anisotropy is generalized for a particle with a uniaxial volume $\left(K_{\mathrm{v}}\right)$ along with a uniaxial surface $\left(K_{\mathrm{s}}\right)$ and unidirectional surface $\left(K_{\mathrm{u}}\right)$ anisotropies. For this case, the resonance field at arbitrary angles $\theta$ between the external field and the particle axis is written in the form

$$
H_{\text {res }}=\left(\frac{\omega}{\gamma}\right)-\left[\frac{2 K_{\mathrm{v}}}{M}+\frac{3 K_{\mathrm{s}}}{M R}\right] P_{2}(\cos \theta)-\frac{3 K_{\mathrm{u}}}{M R},
$$

where $R$ is the radius of nanoparticle and $P_{2} \cos \theta=1 / 4 \times(3 \cos 2 \theta+1)$ is the second Legendre polynomial. For ultradisperse nanoparticles, the magnetic fields of surface anisotropy $\left(K_{\mathrm{s}} / M R\right.$ and $\left.K_{\mathrm{u}} / M R\right)$ far exceed the magnetic field of volumetrical anisotropy $\left(K_{\mathrm{v}} / M\right)$.

The widest line is observable in sample $\mathrm{S}_{2.5}: \Delta H_{\mathrm{FMR}}(c=2.5)=1100$ Oe. The FMR signal in sample $\mathrm{S}_{2.5}$ is by $300-400$ Oe wider than that of neighbors with $c=2$ and 3. Obviously, such a broadening is also due to the magnetic field of surface anisotropy and, possibly, some contribution of magnetic dipole-dipole interactions to the width of the line.

\section{CONCLUSION}

Single-domain nickel nanoparticles encapsulated by a graphite-like shell, the Ni@C nanocomposites, were synthesized by solid-phase pyrolysis of solid solutions of nickel-phthalocyanine-metal-free phthalocyanine $(\mathrm{NiPc})_{x}\left(\mathrm{H}_{2} \mathrm{Pc}\right)_{1-x}$, where $0 \leq x \leq 1$. The dilution of nickel-phthalocyanine with the metalfree phthalocyanine and the variation of parameters of solid phase pyrolysis (temperature, time and pressure) gives a unique opportunity to obtain the $\mathrm{Ni} @ \mathrm{C}$ nanocomposites with the sizes in a wide range and an atomic concentration in the range $0-3$ at\% (0-12 wt\%). Single-domain nickel nanoparticles with average sizes from 4 to $45 \mathrm{~nm}$ were studied. The X-ray diffraction data and the TEM images show that Ni nanoparticles have a face-centered cubic lattice and are distributed in the carbon matrix fairly uniformly. The spectra of FMR and EPR of $\mathrm{Ni} @ \mathrm{C}$ nanocomposites are investigated at room temperature. In the case of ultradisperse Ni nanoparticles, a significant shift of the resonance field was revealed and the broadening of the resonance absorption line in the FMR spectra, in the range 1-10 nm, which corresponds to the range of quantum dots. The data were interpreted taking into account the essential contribution of the surface magnetic anisotropy, whose magnetic field far exceeds the magnetic field of volumetrical anisotropy.

\section{ACKNOWLEDGMENTS}

The study was carried out with the financial support of the SCS MES of Armenia within the framework of the scientific project no. 15t-1c249.

\section{REFERENCES}

1. Gubin, S.P., Magnetic Nanoparticles, Weinheim: Wiley, 2009.

2. Guimaraes, A.A., Principles of Nanomagnetism, Berlin, Heidelberg: Springer-Verlag, 2009.

3. Skomski, R., J. Phys: Condens. Matter, 2003, vol. 15, p. R841. 
4. Huang, K.C., J. Phys. D: Appl. Phys., 2010, vol. 43, p. 374001.

5. Pankhurst, Q.A., Thank, N.T.K., Jones, S.K., and Dobson, J., J. Phys. D: Appl. Phys., 2009, vol. 42, p. 224001.

6. Zhentao, L., Chao, H., Chang, Y., and Jieshan, Q., J. Nanosci. Nanotechnol., 2009, vol. 9, p. 7473.

7. Ibrahim, E.M.M., Hampel, S., Kamsanipally, R., Thomas, J., Erdmann, K., Fuessel, S., Taeschner, C., Khavrus, V.O., Gemming, T., Leonhardt, A., and Buechner, B., Carbon, 2013, vol. 63, p. 358.

8. Huang, H., Xie, Q., Kang, M., and Zhang, B., Nanotechnology, 2009, vol. 20, p. 365101.

9. Park, J.K., Jung, J., Subramaniam, P., and Shah, B.P., Small, 2011, vol. 7, p. 1647.

10. Manukyan, A.S., Mirzakhanyan, A.A., Badalyan, G.R., Shirinyan, G.H., and Sharoyan, E.G., J. Contemp. Phys. (Armenian Ac. Sci.), 2010, vol. 45, p. 132.

11. Manukyan, A.S., Mirzakhanyan, A.A., Badalyan, G.R., Shirinyan, G.H., Fedorenko, A.G., Lianguzov, N.V., Yuzyuk, Yu.I., Bugaev, L.A., and Sharoyan, E.G., J. Nanopart. Res., 2012, vol. 14, p. 982.

12. Manukyan, A.S., Mirzakhanyan, A.A., Khachatryan, T.K., Badalyan, G.R., Abdulvakhidov, K.G., Bugaev, L.A., and Sharoyan, E.G., J. Contemp. Phys.(Arenian Ac. Sci.), 2012, vol. 47, p. 292.

13. Manukyan, A.S., Mirzakhanyan, A.A., Khachatyran, T.K., Badalyan, G.R., Arzumanyan, G.M., and Sharoyan, E.G., J. Contemp. Phys. (Armenian Ac. Sci.), 2013, vol. 48, p. 43.

14. Manukyan, A.S., Mirzakhanyan, A.A., Khachaturyan, R.D., Gyulasaryan, H.T., Kocharian, A.N., Yuzyuk, Yu.I., and Sharoyan, E.G., J. Contemp. Phys. (Armenian Ac. Sci.), 2015, vol. 50, p. 195.

15. Sharoyan, E., Mirzakhanyan, A., Gyulasaryan, H., Sanchez, C., Kocharian, A., Bernal, O., and Manukyan, A., IEEE Transactions on Magnetics, 2016, vol. 52, p. 1.

16. Kong, L., Lu, X., Bian, X., Zhang, W., and Wang, C., ACS Appl. Mater. Inter., 2011, vol. 3, p. 35.

17. Tartaj, P., Morales, M.P., Veintemillas-Verdaguer, S., Gonzalez-Carreno, T., and Serna, C.J., J. Phys. D: Appl. Phys., 2003, vol. 36, p. 182.

18. Kats, E. and Willner, I., Angew Chem. Int. Ed., 2004, vol. 43, p. 6042.

19. Teng, M.-H., Tsai, S.-W., and Chio, W.-A., Alloys and Compounds, 2010, vol. 495, p. 488.

20. Liu, Z., Lv, C., and Tan, X., Phys. Chem. Solids, 2013, vol. 74, p. 1275.

21. Uhm, Y.R., Lee, H.M., and Rhee, C.K., IEEE Transactions on Magnetics, 2009, vol. 45, p. 2453.

22. El-Gendy, A.A., Ibrahim, E.M.M., Khavrus, V.O., Krupskaya, Y., Hampel, S., Leonhardt, A., Buechner, B., and Klingeler, R., Carbon, 2009, vol. 47, p. 2821.

23. Tsurin, V.A., Yermakov, A.Ye., Uimin, M.A., Mysik, A.A., Shchegoleva, N.N., Gaviko, V.S., and Maikov, V.V., Phys. Solid State, 2014, vol. 56, p. 287.

24. Lee, S.J., Jung, J., Kim, M.A., Kim, Y.-R., and Park, J.K., J. Mater. Sci., 2012, vol. 47, p. 8112.

25. Kittel, C., Introduction to Solid State Physics, New York: Wiley, 2005.

26. Morrish, A.H., The Physical Principles of Magnetism, New York: Institute of Electrical and Electronic Engineers, 2001.

27. Singh, V. and Seehra, M.S., J. Phys.: Condens. Matter, 2009, vol. 21, p. 456001.

28. Berger, R., Bissey, J.-C., and Kliava, J., J. Phys.: Condens. Matter., 2000, vol. 12, p. 9347.

29. Berger, R., Bissey, J.-C., Kliava, J., Daubric, H., and Estournes, C., J. Magn. Magn. Mater., 2001, vol. 234, p. 535.

30. Van Vleck, J.H., Phys. Rev., 1950, vol. 78, p. 266.

31. Dorfman, Y.G., JETP, 1965, vol. 21, p. 472.

32. Petrov, Yu.I., Fizika malykh chastits (Physics of Small Particles), Moscow: Nauka, 1982.

33. Bodker, F., Morup, S., and Linderoth, S., Phys. Rev. Lett., 1994, vol. 72, p. 282.

34. Shilov, V.P., Bacri, J.-C., Gazeau, F., Gendron, F., Perzynski, R., and Raikher, Y.L., Phys. Rev. B, 1999, vol. 60, p. 11902.

35. Shilov, V.P., Bacri, J.-C., Gazeau, F., Gendron, F., Perzynski, R., and Raikher, Y.L., J. Appl. Phys., 1999, vol. 85, p. 6642 .

36. Neel, L., J. Phys. Rad., 1954, vol. 15, p. 225.

37. Brown Jr., W.F., Micromagnetics, New York: John Wiley \& Sons, 1963.

38. Aharoni, A., J. Appl. Phys., 1987, vol. 61, p. 3302.

39. Aharoni, A., J. Appl. Phys., 1988, vol. 64, p. 6434. 